\title{
Animal models of scarring control
}

\author{
David L. Williams ${ }^{1}$
}

Received: 25 September 2019 / Accepted: 8 October 2019 / Published online: 10 December 2019

(c) The Royal College of Ophthalmologists 2019

\begin{abstract}
Filtration surgery has, for the past 50 years been key in the treatment of glaucoma yet a significant issue in the long-term success of such surgery is fibrosis limiting aqueous drainage. Numerous methods have been used to reduce such scarring after filtration surgery and animal models have been important in the development of such techniques. First animal models have been central in understanding molecular and cellular changes occurring in fibrosis and thus which pathways might be valuable therapeutic. Secondly animal models have been critical in determining which of these therapies is likely to be most worthwhile. Having said that animals differ substantially from humans in the anatomy of their aqueous drainage pathways and in the mechanisms of fibrotic change. Rodents and lagomorphs vary more markedly from humans than do primates at an anatomic, biochemical and physiological level, and thus the latter might seem more appropriate as models for antifibrotic techniques. However the welfare implications, and thus ethical issues, in using primates are more concerning than with rodents or rabbits and efforts to refine, reduce and replace living animals in such model systems are crucially important. One problem is that the animal models normally involve healthy eyes, not ones with glaucoma. In veterinary ophthalmology we see large numbers of dogs with glaucoma, many of which have filtration implants placed. Potentially these could be a valuable animal model where benefits of antifibrotic treatment could benefit the animals involved and the research seeking to optimise such treatments.
\end{abstract}

\section{Introduction}

How appropriate it is to discuss animal models of ocular scarring in 2019, a year which is the fiftieth anniversary of Molteno's first paper on a glaucoma implant [1]. He used the rabbit to develop the implant although the earliest attempts were trialled immediately on human patients given the severity of uncontrolled glaucoma with use of a transcorneal horse hair employed by Rollett and Moreau [2] or a translimbal silk thread used by Zorab both of these more than a century ago [3]. One year earlier than Molteno's device, John Cairns, working at Addenbrooke's hospital in Cambridge with Peter Watson who founded the Cambridge Ophthalmic Symposium, devised the trabeculectomy $[4,5]$. They did not use an animal model but began by using the technique on two hundred human patients comparing ab externo and $a b$ interno techniques directly, demonstrating that in a disease

David L. Williams

dlw33@cam.ac.uk

1 Department of Veterinary Medicine, University of Cambridge, Madingley Road, Cambridge, UK which was bound to cause blindness, a leap straight to human patients was acceptable, at least 50 years ago when medical ethical review itself was in its infancy [6]! Using more advanced implants to drain aqueous in glaucomatous eyes necessarily require animal models to optimise their development. Even so all implants eventually failed. Molteno noted in his 1969 paper that 'this failure of drainage has been ascribed to fibrosis in the bleb wall, the fibrosis itself being caused by a hypothetical action of the draining aqueous on the tissues'. That quotation shows that the key question is not so much design of the device but overcoming fibrosis around it and indeed fibrosis when no implant is used. Animal models help in that quest first by helping us understand what is causing the fibrosis and secondly by proving a living system, in which mechanisms to reduce scarring can be tested. We might suggest that ex vivo systems such as human Tenon's fibroblast cultures [7] or cultured episcleral explants [8] should be used rather than employing animal models. And indeed these can be valuable and play a key part in investigation of treatment regimes to limit fibrosis in filtration surgery. Sixty years ago this year in 1959 WMS Russell and RL Burch published their ground breaking monograph 'The Principles of Humane Experimental Technique' in which they outlined the three Rs of refinement, reduction and 
replacement of animals in research [9]. Refinement in the studies we are discussing here involves ensuring that the animal models are close to the human eye as possible. Reduction means seeking where possible to limit the number of animals used in such research. And replacement involves the use in vitro systems rather than in vivo models using live animals. Having said that it is important as well to use whole animal models where the long-term changes of fibrosis can be evaluated in a living system. We can tell much regarding fibroblast proliferation or inflammatory processes from cell or explant cultures but it is only by using an animal model that we can tell how therapeutic regimes change filtration processes.

But first we have to ask if use of animal models is appropriate. Quite apart from ethical issues which we have neither the time nor the space to discuss here, the question remains first whether animals are a good model of fibrosis in human patients at a molecular and cellular level and second whether they reflect the effects of ocular fibrosis in humans at an anatomical and physiological level.

Taking the second question first, the aqueous drainage pathways of subprimate mammals are quite different from those of humans since the former, be they rabbits, mice, rats or dogs have the trabecular meshwork at the apex of the iridocorneal angle rather than in the corneoscleral location in primates including humans. This means that trabeculectomies which work so well in humans are not effective in companion animal species with glaucoma be they dogs or rabbits. Surgical treatment to increase aqueous drainage in these animals require gonioimplants such as the Ahmed or Baerveldt devices rather than simple trabeculectomies $[10,11]$. The major problem with such implants in veterinary patients today is just what Molteno noted above 50 years ago, that peri-implant fibrosis causes relatively rapid failure of control of intraocular pressure [12]. Here then is the conundrum - the animal best suited as a model of surgery to the human trabecular meshwork is a primate such as a monkey or higher ape. Yes the ethical and welfare implications of using such animals where subprimate animals are available render their use difficult to justify. If we are looking at using a model system to limit fibrosis may be we do not need one which is anatomically identical to the human iridocorneal angle and trabecular meshwork. May be having one where the molecular mechanisms of fibrosis are similar is sufficient. Yet here we must return to the first of the two questions outlined above. Are rabbits and mice good models of human fibrosis at a molecular and cellular level? Fibrosis in the animal models used is generally significantly more severe than in the Caucasian human eye. Indeed the fibrosis which characterises such implant failure is reminiscent of that seen in Afro-Caribbean patients where fibrosis giving keloid scars is also common [13, 14]. Whether the same gene signature seen in these human patients $[15,16]$ is occurring in subprimate mammals such as the mouse, rabbit or dog is unclear. We might ask, given this difference in severity of fibrosis between different species, whether or not we see the same pathways of fibrosis in animal models and veterinary patients as occurs in humans?

\section{Pathways of fibrosis}

The answer to that question would appear to be affirmative. Indeed our understanding of the mechanisms of fibrosis has come through a mix of in vitro models, animal experimentation and evaluation of pathology in human patients, as we shall see below. Fibrosis be considered as an aberrant form of wound healing. The three key phases of wound healing are first haemostasis where a fibrin clot and a platelet plug form, secondly an inflammatory phase where phagocytic neutrophils and monocytes secrete proteolytic enzymes and proinflammatory cytokines and finally a proliferative phase where granulation tissue forms beneath the epithelium. In this phase angiogenesis forms new blood vessels and fibrinogenesis synthesises loose connective tissue. Growth factors and cytokines are key in this phase, platelet-derived growth factor stimulates inflammatory cells and fibroblasts to produce transforming growth factor beta, perhaps the key player in the development of fibrosis. TGF$\beta$ acts on fibroblasts turning them into myofibroblasts which act as smooth muscle cells remodelling local extracellular matrix by producing alpha smooth muscle actin and giving them contractile activity. Ian Darby's group were among the first to evaluate cell types in fibrosis in animal models back in the early 1990s working with experimentally induced skin wounds in rats $[17,18]$ although Gabbiani et al. had recognised modified fibroblasts in granulation tissue 20 years earlier [19]. Myofibroblasts produce excessive and often aberrant extracellular matrix with tractional forces producing tissue distortion in scarring.

The key features of any therapeutic regime to limit fibrosis therefore should centre around limiting the generation and activity of myofibroblasts. Cellular damage is a key factor in their generation, though given that any drainage surgery be it trabeculectomy or drainage implant engrafting involves some tissue damage this would appear an inevitable part of any glaucoma surgery. Leucocyte in filtration after surgery is a second important influence through chemoattractants such as macrophage inflammatory protein 1a (CCL3) and monocyte chemoattractant protein-1 (CCL2) as they stimulate influx of profibrotic mononuclear phacyocytes which themselves produce profibrotic cytokines such as IL-13. All this is part of the innate immune system but the adaptive immune system also plays a part. $\mathrm{CD} 4^{+} \mathrm{T}$ cells play a critical role in fibrosis in diseases such 
as scleroderma and pulmonary fibrosis. Considerable research has been undertaken on animal models of idiopathic pulmonary fibrosis particularly using bleomycininduced fibrosis in mice [20], of renal fibrosis using mercuric chloride, vanadate or uranyl nitrate in SpragueDawley rats which are specifically more sensitive to fibrosis than other strains [21] or hepatotoxin-induced fibrotic liver disease in rodents Th2 cytokines such as IL-4, IL-5, IL-13 and IL-21 have been shown to be central in the fibrosis occasioned in those diseases [22]. Is the same the case in fibrosis after glaucoma surgery?

\section{The immunological environment of the ocular surface ad anterior chamber}

We know that the ocular surface exhibits a predominantly Th2-associated immunologically privileged environment in common with other mucosal-associated lymphoid tissue as demonstrated in several animal models [23, 24]. Indeed we have to remember that our understanding of the helper T-cell dichotomy comes from work done on mouse models [25] Or does it? Tada's work, just cited, was being undertaken concurrently with that of Evan's lab showing the same T-cell subset populations in human lymphocytes [26]. The laboratory rodent and human work go hand in hand in order to identify the intricacies of the immune system but also to show how what is discovered in the mouse is relevant to the human patient. The same is true for the immunologically privileged status of the anterior chamber. The cells participating in immune responses within the eye participate in the camerosplenic axis, in which the splenic microenvironment is again predominantly Th2-based directing CD8 splenic T cells and $\mathrm{B}$ cells secreting non-complement-fixing antibodies to the eye. More importantly from a fibrosis perspective aqueous humour itself is immunosuppressive, specifically through the action of factors such as vasoactive intestinal polypeptide, alpha-melanocyte stimulating hormone, calcitonin gene-related protein, cortisol and crucially also transforming growth factor $\beta$ [27]. This latter growth factor is particularly important in promoting fibrosis. The movement of aqueous through tissues which have undergone filtration surgery will thus bathe them with TGF- $\beta$ and any antigen presenting cell or T-cell activated in the presence of TGF- $\beta$ will themselves secrete the growth factor [28]. So inflammation predisposes to fibrosis wherever it occurs.

\section{Conjunctival fibrosis}

There are specific factors involved in fibrosis occurring in the conjunctiva following filtration surgery in glaucomatous eyes. Is conjunctiva itself predisposed to fibrosis? As we have noted above the ocular surface is itself a Th2 environment and such an immune deviation which aims to reduce inflammation potentially provokes fibrosis. We are not of course talking of a normal conjunctiva but one reacting to injury, that of filtration surgery. Surgery which induces an inflammatory response. Chronic Th2-mediated inflammation has been shown to induce generation of growth factors by connective tissue in a rat model of liver injury [29] and through release of mediators such as tumour necrosis factor-alpha and TGF-beta involved in acute tissue injury and later chronic fibrosis in the rat lung [30]. Having said that one must ask how relevant hepatic or pulmonary fibrosis is to conjunctival disease processes. Animal models of conjunctival wound healing have been developed in rabbits [31, 32], rats [33, 34], mice [35, 36], and owl monkeys [37, 38]. The rabbit and primate models have the benefit of larger globe size but the mouse models excel in allowing advanced techniques of molecular biology to create valuable models such as gene knockout mice on the one hand [39] and RNA interference of gene transcription on the other [40]. Well before these studies though animal models were used to investigate the use of antimetabolites such as mitomycin and 5-fluorouracil [41-43] and prolonged release steroids [44]. The trouble with all these treatments is that these antimetabolites and steroids have much more widespread results that specific directed actions on fibroblasts; they may cause widespread cell death through apoptosis [45] or even necrosis leading to postoperative hypotony, bleb leakage or even endophthalmitis.

\section{Therapeutic methods to reduce fibrosis}

This is not the place for a full evaluation of agents used to reduce periocular fibrosis and the place of animal models in their development. Reviews undertaking that task are readily available in the literature [46, 47]. Here we will evaluate therapeutic regimes against two key molecules in fibrosis.

We noted above the central role played by TGF- $\beta$ in fibrosis. Our understanding of the function and mechanism of action of this growth factor is based initially on work by Roberts et al. [48] on a rat kidney sarcoma from which she derived two growth factors, TGF- $\alpha$ with effects similar to epidermal growth factor and TFG- $\beta$ itself with remarkable effects on stimulating cell growth and transforming cell phenotype [49]. TFG- $\beta$ exists in three isoforms and is secreted in an inactive homodimer the latency-associated peptide or LAP. This is activated through proteolysis by enzymes such as plasmin or cathepsin, activity of reactive oxygen species and more specifically through interaction with another molecule, thrombospondin. Studies elucidating these pathways can be undertaken in cell-free systems. 
Although work more specifically on conjunctival and episcleral responses to the growth factor have used cultured human tenon's fibroblasts [50]. But full evaluation of the effect of TFG- $\beta$ on effects such as conjunctival scarring which involve interactions between cells and extracellular matrix [51] and results of the use of agents to inhibit TFG- $\beta$ to reduce fibrosis in filtration surgery be they monoclonal antibodies [52] or antisense RNA [53] do require in vivo animal models before use in human patients. It is impressive however to see the rapidity with which an antibody against TFG- $\beta$ was taken from evaluation in the rabbit model published in 1999 [54] to the first randomised controlled study in 24 human patients reported in 2002 [55]. Data from two phase III studies was reported only 3 years later [5658] although with negative results, finding that the antibody as no more efficacious than phosphate-buffered saline. How are we to square the circle of positive results from animal models and yet failure in human patients? Perhaps it is that the animal models are not similar enough to human glaucomatous eyes, do not manifest the range of pathology seen in what we might call 'real life' glaucoma. Perhaps we have not learned enough from the basic science models of what happens in post-surgical fibrosis. It does seem, as we noted above, that TGF- $\beta$ is a key molecule in fibrosis but perhaps targeting that molecule on its own is not sufficient. Perhaps the time course of fibrosis is much longer than was anticipated with treatment with anti-TGF- $\beta$ antibodies in the few weeks after surgery. It may be that fibrosis in animal models acts far faster than in human patients - after all rabbits live for perhaps 6-8 years and this decreased life expectancy from human patients is reflected in higher metabolic rates in these smaller animals [59]. If this is the case other therapeutic regimes which seem to work in animal models may not benefit human patients. Antisense nucleotides oligonucleotides against TGF- $\beta$ have been shown to reduce fibrosis in the rabbit model [53] but we do not know how this will translate to human patients. Similarly Rho kinase inhibitors appear to work well to reduce fibrosis in the rabbit model of glaucoma filtration surgery [60] but we do not as yet have evidence for a translation to human patents.

Other antifibrotic agents with activity to inhibit the activity of TGF- $\beta$ have been studied. The antifibrotic Suramin, first developed by Bayer in the 1920s and now seen to be a TGF- $\beta$ blocker, had been used against onchocerciasis [61] and has been trialled in filtration surgery in the rabbit model with favourable effects with regard to time to surgical failure, bleb morphology and histopathology compared with animals in which mitomycin was employed [62]. The same authors reported an unmasked study of the drug in ten human patients 3 years later with an 18 month follow-up period demonstrating how quickly experimental results can translate to human outcomes if the safety of the agent is already recognised
[63], although no further large-scale studies have been conducted.

Another key molecule in fibrosis is vascular endothelial growth factor (VEGF) with actions with which we are all familiar with regard to age-related macular degeneration in promoting angiogenesis but also stimulating fibrosis. The first studies on VEGF involved Folkman's identification of an angiogenic factor from tumours from human patients [64], while Senger was able to characterise the molecule more from ascitic fluid in laboratory animals, in which tumours had been implanted [65]. Final cloning of the gene for VEGF came through its isolation from bovine pituitary extracts [66]. Experimental studies on the rabbit filtration surgery model were published by Memarzadeb et al. [67]. But interestingly patients had already been treated off-label with the antibody in Avastin, this study reported in 2008 [68], before the Memarzadeb paper we have just referenced [57] so one might ask why an animal model is required. This sort of a small human study — the Grewal et al. paper [68] involved 12 patients-does not allow comparison between treated and control patients as did Memarzadeb et al.'s study [67] nor assessment of drug safety [69] or pharmacokinetics [70]. In all these an animal model is essential, or may be we should say valuable and highly desirable. The issue, as with TGF- $\beta$ studies detailed above, is whether the results from laboratory animal experiments are readily translatable to the human patient. Pilot studies have investigated the effect of antiVEGF antibodies in glaucoma shunt surgery [71, 72] but side effects have been noted [73] and these studies are not controlled comparative trials. A more recent report compares the results of sub-conjunctival injection of conbercept an antiVEGF antibody as an adjuvant to filtration surgery with five fluorouracil with promising results [74] but again we have no larger controlled studies to rely on. How can we seek to bridge this divide between laboratory animal studies which seem to be promising and trials in populations of human patients which are less efficacious?

\section{Companion animals as valuable models for glaucoma treatment?}

One of the problems with the animal models is that they do not adequately mirror the problems of glaucoma in the human patient. Perhaps using spontaneously occurring disease in companion animals as models for human disease would be helpful. Glaucoma is as common a cause of blindness in dogs as it is in human patients, with 89 cases of breed-related inherited glaucoma seen in every 10,000 pedigree dogs in the recent survey available (Fig. 1a) [75]. Treatment protocols range from medical therapy, through cyclodestructive techniques such as endolaser cyclophotocoagulation to gonioimplants (Fig. 1b) [76]. With regard to 


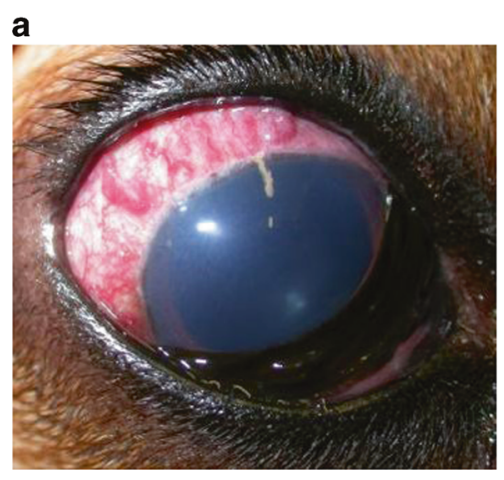

b

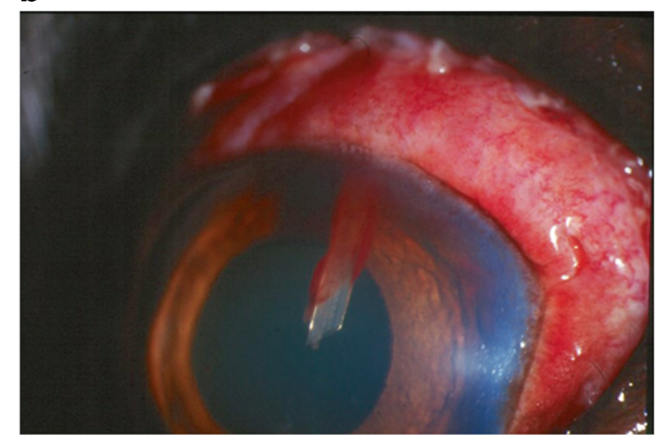

c

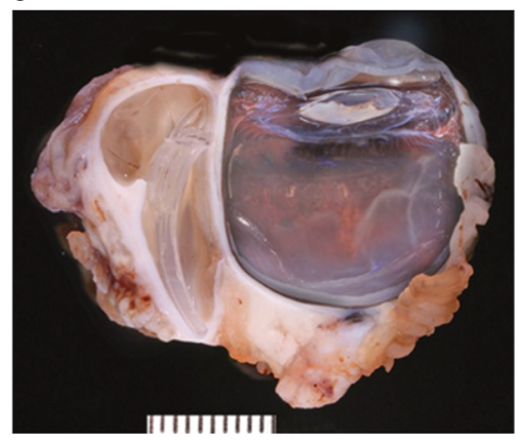

Fig. 1 The dog as a model for glaucoma therapy. a A basset hound with angle-closure glaucoma and a pressure of $56 \mathrm{mmHg}$. b A glaucomatous eye in a spaniel treated with a Joseph drainage implant. c Post-enucleation specimen showing marked peri-implant fibrosis.

the latter therapeutic option fibrosis after filtration implant surgery is as concerning a problem in glaucomatous dogs as it is in people (Fig. 1c). Mitomycin C was used from the 1990s to reduce fibrosis around filtration implants [77] and still 20 years later novel systems were being developed to optimise mitomycin delivery for canine glaucoma filtration devices [78]. The problem here is that there is a divide between human and canine ophthalmic medicine and science. Veterinary ophthalmologists use techniques and treatments developed for human patients, but there is little translation of veterinary techniques and products to ophthalmology for human patients. We can see this particularly in treatment for dry eye. Back in the late 1980s topical cyclosporine was found to increase tear production in dogs with keratoconjunctivitis and this as a licensed product Optimmune has revolutionised the treatment of canine keratoconjunctivitis sicca [79, 80]. And yet it was not for 10 years that studies confirmed that the drug had the same effect in human patients [81] and another 10 before the drug was licensed as Restasis in the United States [82]. Now, truth be told, we do not have a new drug used in dogs but not yet in people which prevents fibrosis in the same way that topical cyclosporine was used to combat dry eye in dogs years before it was available for human patients, so the comparison is not exact. Even so I would like to suggest a much closer interaction between medical and veterinary ophthalmologists so that dogs with spontaneous inherited glaucoma could serve as models for therapeutic regimes used also in people. One recent example of just such a collaboration is the transcorneal Brown drainage implant [83] evaluated simultaneously in human and canine patients with extremely promising results $[84,85]$. This device overcomes of the problems with peri-implant fibrosis as a microporous filter membrane allows passage of aqueous from the anterior chamber to the tear film giving a final intraocular pressure of $12 \mathrm{mmHg}$. A bio-inert coating prevents cellular ingrowth resulting in fibrosis, in the patent noted above [83]. Perhaps after a paper discussing medical methods of reducing fibrosis the best result will be an inert coating on a trans-scleral implant avoiding fibrosis without resort to antimetabolites or antibodies. Only time will tell.

\section{Conclusion}

Animal studies are central in identifying and developing antifibrotic regimes to improve the results of glaucoma filtration. First animal studies are needed to identify the molecules central in the biology of fibrosis and their role in the genesis of fibrotic responses of tissues. Secondly animal models are needed to identify and develop methods of delivering these novel treatments. In all these, however, it is essential that animal use is optimised to refine, reduce and replace work on live animals wherever possible. With regard to fibrosis in glaucoma filtration surgery work on rabbits and rodents has been valuable in some respects but in others translation of success in these animal models into treatment for glaucoma in human patients has not been particularly successful. It may be that the experimental models used are not as valuable as naturally occurring cases of glaucoma in companion animals where use of novel treatments could be valuable in resolving glaucoma in each animal and providing useful information for the development of new techniques to improve glaucoma surgery in human patients.

\section{Compliance with ethical standards}

Conflict of interest The authors declare that they have no conflict of interest.

Publisher's note Springer Nature remains neutral with regard to jurisdictional claims in published maps and institutional affiliations.

\section{References}

1. Molteno AC. New implant for drainage in glaucoma. Animal trial. Br J Ophthalmol. 1969;53:161. 
2. Rollett M, Moreau M. Le drainage au crin de la chambre anterieure contre l'hypertonie et la douleur. Rev Gen Ophtalmol. 1907;26:289-92.

3. Zorab A. The reduction of tension in chronic glaucoma. Ophthalmoscope. 1912;10:258-61.

4. Cairns JE. Trabeculectomy: preliminary report of a new method. Am J Ophthalmol. 1968;66:673-9.

5. Watson PG. Trabeculectomy, a modified ab externo technique. Ann Ophthalmol. 1970;2:199-205.

6. Beecher HK. Ethical and clinical research. $\mathrm{N}$ Engl J Med. 1966;274:1354-60.

7. Mietz H, Chévez-Barrios P, Lieberman MW, Wendt M, Gross R, Basinger SF. Decorin and suramin inhibit ocular fibroblast collagen production. Graefes Arch Clin Exp Ophthalmol. 1997;235: 399-403.

8. Johnson DH, Bradley JM, Acott TS. The effect of dexamethasone on glycosaminoglycans of human trabecular meshwork in perfusion organ culture. Investig Ophthalmol Vis Sci. 1990;31: 2568-71.

9. Russell WM, Burch RL, Hume CW. The principles of humane experimental technique. London: Methuen; 1959.

10. Sapienza JS, Van Der Woerdt A. Combined transscleral diode laser cyclophotocoagulation and Ahmed gonioimplantation in dogs with primary glaucoma: 51 cases (1996-2004). Vet Ophthalmol. 2005;8:121-7.

11. Graham KL, Donaldson D, Billson FA, Billson FM. Use of a 350$\mathrm{mm} 2$ Baerveldt glaucoma drainage device to maintain vision and control intraocular pressure in dogs with glaucoma: a retrospective study (2013-2016). Vet Ophthalmol. 2017;20:427-34.

12. Westermeyer HD, Hendrix DV, Ward DA. Long-term evaluation of the use of Ahmed gonioimplants in dogs with primary glaucoma: nine cases (2000-2008). J Am Vet Med Assoc. 2011;238: 610-7.

13. Broadway D, Grierson I, Hitchings R. Racial differences in the results of glaucoma filtration surgery: are racial differences in the conjunctival cell profile important? Br J Ophthalmol. 1994;78: 466-75.

14. Halim AS, Emami A, Salahshourifar I, Kannan TP. Keloid scarring: understanding the genetic basis, advances, and prospects. Arch Plast Surg. 2012;39:184-9.

15. Yu-Wai-Man C, Tagalakis AD, Meng J, Bouremel Y, Lee RM, Virasami A, et al. Genotype-phenotype associations of IL6 and PRG4 with conjunctival fibrosis after glaucoma surgery. JAMA Ophthalmol. 2017;135:1147-55.

16. Yu-Wai-Man $\mathrm{C}$, Owen $\mathrm{N}$, Lees $\mathrm{J}$, Tagalakis $\mathrm{AD}$, Hart $\mathrm{SL}$, Webster AR, et al. Genome-wide RNA-sequencing analysis identifies a distinct fibrosis gene signature in the conjunctiva after glaucoma surgery. Sci Rep. 2017;7:5644.

17. Darby IA, Hewitson TD. Fibroblast differentiation in wound healing and fibrosis. Int Rev Cytol. 2007;257:143-79.

18. Darby I, Skalli O, Gabbiani G. a-Smooth muscle actin is transiently expressed by myofibroblasts during experimental wound healing. Lab Investig. 1990;63:21-9.

19. Gabbiani G, Ryan GB, Majno G. Presence of modified fibroblasts in granulation tissue and their possible role in wound contraction. Experientia. 1971;27:549-50.

20. Tashiro J, Rubio GA, Limper AH, Williams K, Elliot SJ, Ninou I, et al. Exploring animal models that resemble idiopathic pulmonary fibrosis. Front Med. 2017;4:118.

21. Nogueira A, Pires MJ, Oliveira PA. Pathophysiological mechanisms of renal fibrosis: a review of animal models and therapeutic strategies. In Vivo 2017;31:1-22.

22. Delire B, Stärkel P, Leclercq I. Animal models for fibrotic liver diseases: what we have, what we need, and what is under development. J Clin Transl Hepatol. 2015;3:53.
23. Stern ME, Schaumburg CS, Dana R, Calonge M, Niederkorn JY, Pflugfelder SC. Autoimmunity at the ocular surface: pathogenesis and regulation. Mucosal Immunol. 2010;3:425.

24. Steven P, Gebert A. Conjunctiva-associated lymphoid tissuecurrent knowledge, animal models and experimental prospects. Ophthalmic Res. 2009;42:2-8.

25. Tada T, Takemori T, Okumura KO, Nonaka M, Tokuhisa T. Two distinct types of helper $\mathrm{T}$ cells involved in the secondary antibody response: independent and synergistic effects of Ia-and Ia+helper T cells. J Exp Med. 1978;147:446-58.

26. Evans RL, Breard JM, Lazarus H, Schlossman SF, Chess L. Detection, isolation, and functional characterization of two human T-cell subclasses bearing unique differentiation antigens. J Exp Med. 1977;145:221-33.

27. Koevary SB. Ocular immune privilege: a review. Clin Eye Vis Care. 2000;12:97-106.

28. Streilein JW. Molecular basis of ACAID. Ocul Immunol Inflamm. 1997;5:217-8

29. Tan Z, Qian X, Jiang R, Liu Q, Wang Y, Chen C, et al. IL-17A plays a critical role in the pathogenesis of liver fibrosis through hepatic stellate cell activation. J Immunol. 2013;191:1835-44.

30. Kolb M, Margetts PJ, Anthony DC, Pitossi F, Gauldie J. Transient expression of IL-1 $\beta$ induces acute lung injury and chronic repair leading to pulmonary fibrosis. J Clin Investig. 2001;107:1529-36.

31. Sherwood MB. A sequential, multiple-treatment, targeted approach to reduce wound healing and failure of glaucoma filtration surgery in a rabbit model (an American Ophthalmological Society thesis). Trans Am Ophthalmol Soc. 2006;104:478.

32. Miller MH, Grierson I, Unger WI, Hitchings RA. Wound healing in an animal model of glaucoma fistulizing surgery in the rabbit. Ophthalmic Surgery, Lasers and Imaging. Retina. 1989;20:350-7.

33. Sherwood MB, Esson DW, Neelakantan A, Samuelson DA. A new model of glaucoma filtering surgery in the rat. J Glaucoma. 2004;13:407-12.

34. Sheridan CM, Unger WG, Ayliffe W, Alam Y, Goldsmith J, O'donoghue E, et al. Macrophages during fibrosis following scleral fistulising surgery in a rat model. Curr Eye Res. 1996;15: 559-68.

35. Mietz H, Chévez-Barrios P, Lieberman MW. A mouse model to study the wound healing response following filtration surgery. Graefes Arch Clin Exp Ophthalmol. 1998;236:467-75.

36. Reichel MB, Cordeiro MF, Alexander RA, Cree IA, Bhattacharya SS, Khaw PT. New model of conjunctival scarring in the mouse eye. Br J Ophthalmol. 1998;82:1072-7.

37. Desjardins DC, Parrish RK, Folberg R, Nevarez J, Heuer DK, Gressel MG. Wound healing after filtering surgery in owl monkeys. Arch Ophthalmol. 1986;104:1835-9.

38. Gressel MG, Parrish IIRK, Folberg R. 5-fluorouracil and glaucoma filtering surgery: I. An animal model. Ophthalmology. 1984;91:378-83.

39. Akhurst RJ, Hata A. Targeting the TGF $\beta$ signalling pathway in disease. Nat Rev Drug Discov. 2012;11:790.

40. Nakamura H, Siddiqui SS, Shen X, Malik AB, Pulido JS, Kumar $\mathrm{NM}$, et al. RNA interference targeting transforming growth factorbeta type II receptor suppresses ocular inflammation and fibrosis. Mol Vis. 2004;10:703-11.

41. Bergstrom TJ, Wilkinson WS, Skuta GL, Watnick RL, Elner VM. The effects of subconjunctival mitomycin-C on glaucoma filtration surgery in rabbits. Arch Ophthalmol. 1991;109:1725-30.

42. Khaw PT, Doyle JW, Sherwood MB, Smith MF, McGorray S. Effects of intraoperative 5-fluorouracil or mitomycin $\mathrm{C}$ on glaucoma filtration surgery in the rabbit. Ophthalmology. 1993;100: $367-72$.

43. Cordeiro MF, Constable PH, Alexander RA, Bhattacharya SS, Khaw PT. Effect of varying the mitomycin-C treatment area in 
glaucoma filtration surgery in the rabbit. Investig Ophthalmol Vis Sci. 1997;38:1639-46.

44. SooHoo JR, Seibold LK, Laing AE, Kahook MY. Bleb morphology and histology in a rabbit model of glaucoma filtration surgery using Ozurdex ${ }^{\circledast}$ or mitomycin-C. Mol Vis. 2012;18:714.

45. Crowston JG, Akbar AN, Constable PH, Occleston NL, Daniels JT, Khaw PT. Antimetabolite-induced apoptosis in Tenon's capsule fibroblasts. Investig Ophthalmol Vis Sci. 1998;39:449-54.

46. Lockwood A, Brocchini S, Khaw PT. New developments in the pharmacological modulation of wound healing after glaucoma filtration surgery. Curr Opin Pharmacol. 2013;13:65-71.

47. Seibold LK, Sherwood MB, Kahook MY. Wound modulation after filtration surgery. Surv Ophthalmol. 2012;57:530-50.

48. Roberts AB, Anzano MA, Lamb LC, Smith JM, Frolik CA, Marquardt $\mathrm{H}$, et al. Isolation from murine sarcoma cells of novel transforming growth factors potentiated by EGF. Nature. 1982;295:417-9.

49. Sporn MB. The early history of TGF-beta, and a brief glimpse of its future. Cytokine Growth Factor Rev. 2006;17:3.

50. Chang MR, Cheng QI, Lee DA. Review basic science and clinical aspects of wound healing in glaucoma filtering surgery. J Ocul Pharmacol Ther. 1998;14:75-95.

51. Cordeiro MF, Reichel MB, Gay JA, D'Esposita F, Alexander RA, Khaw PT. Transforming growth factor- $\beta 1,-\beta 2$, and- $\beta 3$ in vivo: effects on normal and mitomycin c-modulated conjunctival scarring. Investig Ophthalmol Vis Sci. 1999;40:1975-82.

52. Mead AL, Wong TT, Cordeiro MF, Anderson IK, Khaw PT. Evaluation of anti-TGF- $\beta 2$ antibody as a new postoperative antiscarring agent in glaucoma surgery. Investig Ophthalmol Vis Sci. 2003;44:3394-401.

53. Cordeiro MF, Mead A, Ali RR, Alexander RA, Murray S, Chen $C$, et al. Novel antisense oligonucleotides targeting TGF- $\beta$ inhibit in vivo scarring and improve surgical outcome. Gene Ther. 2003;10:59.

54. Cordeiro MF, Gay JA, Khaw PT. Human anti-transforming growth factor- $\beta 2$ antibody: a new glaucoma anti-scarring agent. Investig Ophthalmol Vis Sci. 1999;40:2225-34.

55. Siriwardena D, Khaw PT, King AJ, Donaldson ML, Overton BM, Migdal $\mathrm{C}$, et al. Human antitransforming growth factor $\beta 2$ monoclonal antibody-a new modulator of wound healing in trabeculectomy: a randomized placebo controlled clinical study. Ophthalmology. 2002;109:427-31.

56. CAT-152 0102 Trabeculectomy Study Group. A phase III study of subconjunctival human anti-transforming growth factor $\beta 2$ monoclonal antibody (CAT-152) to prevent scarring after firsttime trabeculectomy. Ophthalmology. 2007;114:1822-30.

57. CAT-152 0102 Trabeculectomy Study Group. Trabeculectomy study [letter]. Ophthalmology. 2007;114:1950.

58. Grehn F, Hollo G, Khaw P, Overton B, Wilson R, Vogel R, et al. Factors affecting the outcome of trabeculectomy: an analysis based on combined data from two phase III studies of an antibody to transforming growth factorbeta2, CAT-152. Ophthalmology. 2007;114:1831-8.

59. Martinez MN. Interspecies differences in physiology and pharmacology: extrapolating preclinical data to human populations. Preclinical drug development. New York: CRC Press; 2016. p. 47-82.

60. Van de Velde S, Van Bergen T, Vandewalle E, Kindt N, Castermans K, Moons L, et al. Rho kinase inhibitor AMA0526 improves surgical outcome in a rabbit model of glaucoma filtration surgery. Prog Brain Res. 2015;220:283-97.

61. Anderson J, Fuglsang H. Effects of suramin on ocular onchocerciasis. Tropenmed Parasitol 1976;27:279-96.

62. Mietz H, Chévez-Barrios P, Feldman RM, Lieberman MW. Suramin inhibits wound healing following filtering procedures for glaucoma. Br J Ophthalmol. 1998;82:816-20.
63. Mietz H, Krieglstein GK. Suramin to enhance glaucoma filtering procudures: a clinical comparison with mitomycin. Ophthalmic surgery, lasers \& imaging. Retina. 2001;32:358.

64. Folkman J. Isolation of a tumour factor responsible for angiogenesis. J Exp Med. 1971;133:275-88.

65. Senger DR, Galli SJ, Dvorak AM, Perruzzi CA, Harvey VS, Dvorak HF. Tumor cells secrete a vascular permeability factor that promotes accumulation of ascites fluid. Science. 1983;219:983-5.

66. Ferrara N, Henzel WJ. Pituitary follicular cells secrete a novel heparin-binding growth factor specific for vascular endothelial cells. Biochem Biophys Res Commun. 1989;161:851-8.

67. Memarzadeh F, Varma R, Lin LT, Parikh JG, Dustin L, Alcaraz A, et al. Postoperative use of bevacizumab as an antifibrotic agent in glaucoma filtration surgery in the rabbit. Investig Ophthalmol Vis Sci. 2009;50:3233-7.

68. Grewal DS, Jain R, Kumar H, Grewal SP. Evaluation of subconjunctival bevacizumab as an adjunct to trabeculectomy: a pilot study. Ophthalmology. 2008;115:2141-5.

69. Park HY, Kim SJ, Lee HB, Kim ES, Tchah H. Effect of intracameral bevacizumab injection on corneal endothelium in rabbits. Cornea. 2008;27:1151-5.

70. Kim MJ, Han ES, Kim J, Kim TW. Aqueous humor concentration of bevacizumab after subconjunctival injection in rabbit. J Ocul Pharmacol Ther. 2010;26:49-54.

71. Rojo-Arnao M, Albis-Donado OD, Lliteras-Cardin M, Kahook MY, Gil-Carrasco F. Adjunctive bevacizumab in patients undergoing Ahmed valve implantation: a pilot study. Ophthalmic Surg Lasers Imaging Retin. 2011;42:132-7.

72. Desai RU, Singh K, Lin SC. Intravitreal ranibizumab as an adjunct for Ahmed valve surgery in open-angle glaucoma: a pilot study. Clin Exp Ophthalmol. 2013;41:155-8.

73. Miraftabi A, Nilforushan N. Wound dehiscence and device migration after subconjunctival bevacizumab injection with Ahmed glaucoma valve implantation. J Ophthalmic Vis Res. 2016;11:112.

74. Zhang J, Vikash V, Wang P, Zheng T, Chen DL, Wang Q, et al. Effect of subconjunctival injection with Conbercept as an adjuvant to filtration surgery for open angle glaucoma: a prospective randomized interventional 6-month follow-up study. Int J Ophthalmol. 2019;12:235.

75. Gelatt KN, MacKay EO. Prevalence of the breed-related glaucomas in pure-bred dogs in North America. Vet Ophthalmol. 2004;7:97-111.

76. Komáromy AM, Bras D, Esson DW, Fellman RL, Grozdanic SD, Kagemann L, Miller PE, Moroi SE, Plummer CE, Sapienza JS, Storey ES. The future of canine glaucoma therapy. Vet Ophthalmol. 2019. https://doi.org/10.1111/vop.12678.

77. Glover TL, Nasisse MP, Davidson MG. Effects of topically applied mitomycin-C on intraocular pressure, facility of outflow, and fibrosis after glaucoma filtration surgery in clinically normal dogs. Am J Vet Res. 1995;56:936-40.

78. Kojima S, Sugiyama T, Takai S, Jin D, Ueki M, Oku H, et al. Effects of gelatin hydrogel loading mitomycin $\mathrm{C}$ on conjunctival scarring in a canine filtration surgery model. Investig Ophthalmol Vis Sci. 2015;56:2601-5.

79. Kaswan RL, Salisbury MA, Ward DA. Spontaneous canine keratoconjunctivitis sicca: a useful model for human keratoconjunctivitis sicca: treatment with cyclosporine eye drops. Arch Ophthalmol. 1989;107:1210-6.

80. Williams DL. A comparative approach to topical cyclosporine therapy. Eye. 1997;11:453-64.

81. Sall K, Stevenson OD, Mundorf TK, Reis BL, CsA Phase 3 Study Group. Two multicenter, randomized studies of the efficacy and safety of cyclosporine ophthalmic emulsion in moderate to severe dry eye disease. Ophthalmology. 2000;107:631-9. 
82. Pflugfelder SC. Integrating restasis into the management inti the management of dry eye. International Ophthalmologic. Clinics. 2006;46:101-3.

83. Brown JD. Microoptx Inc, assignee. Glaucoma treatment devices and methods. United States Patent Application US 15/540,904. 28 Dec 2017.

84. Larocca RD, Martin RC. Early results of the veterinary implant glaucoma registry (VIGOR) a multicenter evaluation of the Brown glaucoma implant in canines (abstract). In: Proceedings of the 49th Annual Conference of the American College of Veterinary Ophthalmologists. Minneapolis, USA, 2018;137:87.

85. Martin RC, Baker SR, Render JA, et al. Safety and efficacy evaluation of a nanoengineered, externally communicating, aqueous humor shunt in Yucatan swine (abstract). In: Proceedings of the 49th Annual Conference of the American College of Veterinary Ophthalmologists. Minneapolis, USA, 2018;136. 